\title{
Effects of OMMT on the aging behaviors of halogen-antimony flame-retarded LGFPA6 composites: Flammability and thermal degradation kinetics
}

\author{
Xiaoling Zuo \\ Institut de Science des Materiaux de Mulhouse, shanghai0401@163.com \\ Haishuo Song \\ Guizhou University \\ Huiju Shao \\ Guizhou University
}

See next page for additional authors

Follow this and additional works at: https://arrow.tudublin.ie/scschcpsart

Part of the Chemistry Commons

\section{Recommended Citation}

Zuo, X., Song, H., Shao, H., Au, M. H., Wei, T., \& Guo, J. (2017). Effects of OMMT on the aging behaviors of halogen-antimony flame-retarded LGFPA6 composites: Flammability and thermal degradation kinetics. Thermochimica Acta, 653, 32-42. DOI: 10.1016/j.tca.2017.04.001

This Article is brought to you for free and open access by the School of Chemical and Pharmaceutical Sciences at ARROW@TU Dublin. It has been accepted for inclusion in Articles by an authorized administrator of ARROW@TU Dublin. For more information, please contact arrow.admin@tudublin.ie, aisling.coyne@tudublin.ie, gerard.connolly@tudublin.ie.

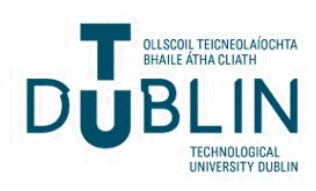




\section{Authors}

Xiaoling Zuo, Haishuo Song, Huiju Shao, Minh Hang Au, Tao Wei, and Jianbing Guo 


\title{
Effects of OMMT on the aging behaviors of halogen-antimony flame- retarded LGFPA6 composites: Flammability and thermal degradation kinetics
}

\author{
Xiaoling Zuo ${ }^{\mathrm{b}, \mathrm{c}, *}$, Haishuo Song ${ }^{\mathrm{a}}$, Huiju Shao ${ }^{\mathrm{a}}$, Minh Hang $\mathrm{Au}^{\mathrm{d}}$, Tao Wei ${ }^{\mathrm{a}}$, Jianbing Guo ${ }^{\mathrm{a}, * *}$

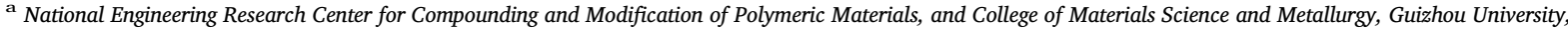 \\ Guiyang, China \\ b Institut de Science des Materiaux de Mulhouse IS2 M, UMR CNRS 7361, UHA, Mulhouse, France \\ c Laboratoire de Chimie Organique et Bioorganique, EA4566, UHA, ENSCMu, Mulhouse, France \\ d School of Chemical and Pharmaceutical Sciences, Dublin Institute of Technology, Dublin, Ireland
}

\section{A R T I C L E I N F O}

\section{Keywords:}

Thermo-oxidative aging

LGFPA6 composites

Flammability

Degradation kinetics

\begin{abstract}
A B S T R A C T
After a long-term thermo-oxidative exposure, compared to the long-glass-fiber reinforced polyamide 6 composite containing halogen-antimony flame retardants (FR/LGFPA6), substitution of a certain content of flame retardants with organo-modified montmorillonite (OMMT) was found to positively affect the FR/LGFPA6 composite in some cases (i.e. flammability and thermal degradation kinetics). The aged OMMT/FR/LGFPA6 composite not only was less flammable but also behaved better in the formation of char residues. All the calculated apparent activation energy obtained by the methods of Friedman, Flynn-Wall-Ozawa and CoatsRedfern in a dynamic measurement showed an obvious increase for the OMMT/FR/LGFPA6 composite after aging, a theoretical evidence for its improved flame retardancy.
\end{abstract}

\section{Introduction}

Recently, the research focus of modification of composites is mainly about using fillers/reinforcements with nano- to macro-scale to fill polymeric matrix. Herein, glass fibers (GF) and flame retardants (FR) have been extensively introduced into materials to improve their mechanical performance and flame resistance, respectively [1-3]. Regarding the flame retardants, of particular interest are studies investigating the synergistic effects of nanoclays with various FR combinations on polymeric materials [4]. Since clay can improve the mechanical and thermal properties of the neat material with the superiorities associated with low cost, few adding quantity and easily processable with polymers [5].

The degradation of materials is an unavoidable phenomenon in a wide range of environments and service conditions, especially during storage and fabrication, thereby resulting in the deteriorated performance $[2,6]$. Interestingly, not all the flammability and/or flame retardancy of the flame-retarded materials would yield to aging. For instance, our group found that thermo-oxidative aging to some extent optimized the flame retardancy of LGFPA6 composites containing tris (tribromophenyl) cyanurate and antimony trioxide $\left(\mathrm{Sb}_{2} \mathrm{O}_{3}\right)$, namely, becoming less flammable and char residues more rich after aging [2]. Besides, Colonna et al. [7a] reported that aging treatment at $90{ }^{\circ} \mathrm{C}$ for $120 \mathrm{~h}$ enormously delayed the time to ignition (TTI) of EVA/clay nanocomposite, from $64 \pm 1$ to $110 \pm 20 \mathrm{~s}$. Lesaffre et al. [7b] researched PLA/ammonium polyphosphate/melamine/clay composites under hydrolysis aging at $50{ }^{\circ} \mathrm{C}$ with $75 \%$ relative humidity. They found that the peak of heat release rate ( $\mathrm{pHRR}$ ) decreased as a function of aging time, from 111 (unaged) to $55 \mathrm{~kW} / \mathrm{m}^{2}$ (46 days aging), meanwhile, accompanied by the increased LOI values, from 43 to $48 \%$. Based on these conclusions, we infer that the major factor can be ascribed to the differences in the anti-aging properties of the different fireretardant formulations. So our interest lies in studying the effects of fire-retarding additives on the aging behaviors of a composite, with special emphasis on the degradation behavior and flammability after a period of aging.

The aim of this work is to study the influences of aging on the flammability and thermal degradation kinetics of LGFPA6 composites containing brominated epoxy resin (BER)- $\mathrm{Sb}_{2} \mathrm{O}_{3}$-organomodified montmorillonite (OMMT) (labeled as OMMT/FR/LGFPA6), compared with those of composites in the absence of OMMT (labeled as FR/LGFPA6). To the best of our knowledge, there is no report about the fire behavior

\footnotetext{
* Corresponding author at: Institut de Science des Materiaux de Mulhouse IS2M, UMR CNRS 7361, UHA, Mulhouse, France.

** Corresponding author.

E-mail addresses: shanghai0401@163.com (X. Zuo), guojianbing_1015@126.com (J. Guo).
} 
of a composite formulated with such hybrid flame retardants being exposed to an accelerated aging treatment condition at $160{ }^{\circ} \mathrm{C}$. For one thing, this given temperature is slightly higher than the glass transition temperature $\left(\mathrm{T}_{\mathrm{g}}\right)$ of BER $\left(\sim 135^{\circ} \mathrm{C}\right.$, provided in Supporting Information Fig. 1). For another, as for the research of surface pile up of silicate lamellas upon high temperature, most treatment temperatures were carried out within the range $180-250{ }^{\circ} \mathrm{C}[8,9]$. Few studies employed a lower heat treatment temperature to analyze this phenomenon. Except that Colonna et al. [7a] pointed out no significant change in the lamellas surface distribution of nanocomposites after aging $120 \mathrm{~h}$ at $90{ }^{\circ} \mathrm{C}$. Additionally, based on our preceding study, aging at $160{ }^{\circ} \mathrm{C}$ could make an appreciable difference in the fire behavior of flame-retarded composites relative to the composites before aging [2]. Thus, $160{ }^{\circ} \mathrm{C}$ is chosen as our accelerated aging temperature in this study.

Evaluations of the surface elemental concentration and the change of surface morphology, would be performed by energy dispersive X-ray spectrometer (EDS) and scanning electronic microscopy (SEM). The combustion and flame retardancy would be studied by the following tests, cone calorimeter test (CONE), limiting oxygen index (LOI) and vertical burning test (UL-94). The morphology and structure of OMMT would be monitored by energy dispersive X-ray spectroscopy (XRD). And the thermal degradation kinetics would be investigated by thermogravimetric analysis (TGA).

\section{Materials and methods}

\subsection{Materials}

The polyamide 6 was a standard viscosity grade product, produced by UBE Co. Ltd, Japan (1013B). The continuous glass fiber rovings (ECT4301H), with a diameter of $17 \mu \mathrm{m}$, treated with a silane coupling agent, were obtained from Chongqing Polycomp International Co. Ltd, China. Brominated epoxy resin was supplied by Shenzhen Kemi Chemical Co. Ltd, China (KM-H01, Fig. 1), with a bromine content of $51-53.0 \%(\mathrm{w} / \mathrm{w})$ and a molecular weight $\left(\mathrm{M}_{\mathrm{w}}\right)$ of 22,000 . Antimony trioxide was produced by Huaxing Loudi Antimony Industry Co. Ltd, China. For nanoparticles, organo-modified montmorillonite DK5, modified by bis-(2-hydroxyethyl)methyl tallowalkyl ammonium cations was supplied by Zhejiang Fenghong New Material Co. Ltd, China. All the products were used as received.

\subsection{Preparation of composites}

At first, all products were dried for $24 \mathrm{~h}$ at $80^{\circ} \mathrm{C}$ in a vacuum oven to remove any moisture before use. The LGFPA6 composites were blended in an intermeshing counter-rotating two-screw extruder (TSE$40 \mathrm{~A}, \mathrm{~L} / \mathrm{D}=40, \mathrm{D}=40 \mathrm{~mm}$, Coperion Keya Machinery, Co., Ltd. China) in a temperature range of $205-240{ }^{\circ} \mathrm{C}$ (maintained $30 \mathrm{wt} \%$ glass fiber loading) with a screw speed of $300 \mathrm{r} / \mathrm{min}$ and cooled down in an impregnation device. Flame retardant masterbatches were prepared by mixing $40 \mathrm{wt} \%$ of PA6 with $50 \mathrm{wt} \%$ of BER and $10 \mathrm{wt} \%$ of $\mathrm{Sb}_{2} \mathrm{O}_{3}$ using the same two-screw extruder in a range of $205-240{ }^{\circ} \mathrm{C}$ with a screw speed of $300 \mathrm{r} / \mathrm{min}^{2}{ }^{2}$ The OMMT/PA6 masterbatches were obtained by mixing together $70 \mathrm{wt} \%$ of PA6 with $30 \mathrm{wt} \%$ of OMMT following the same protocol as outlined above [7d]. All continuous extrudates were then chopped into granules with a length of $12 \mathrm{~mm}$. All granules were dried for $24 \mathrm{~h}$ at $80{ }^{\circ} \mathrm{C}$ under vacuum before injection molding. FR/ LGFPA6 and OMMT/FR/LGFPA6 composites were then injectionmolded (Type CJ80M3V, Chende Plastics Machinery Co., Ltd, China) in a range of $225-270{ }^{\circ} \mathrm{C}$ into various specimens for testing and characterization (detailed process is shown in Fig. 2). The mass percentage of each component for both composites is listed in Table 1.

Before oven aging, all samples were dried at $80^{\circ} \mathrm{C}$ for $24 \mathrm{~h}$ under vacuum [2]. Aging of composites was carried out in a circulating air oven (GZX-9240 ME, Boxun, China) at $160{ }^{\circ} \mathrm{C}$ for 30 days (the temperature fluctuation range is limited within $\pm 1{ }^{\circ} \mathrm{C}$ ). After they were taken out, sealed in a desiccator for $24 \mathrm{~h}$ and then subjected to characterizations. The changes of various properties for the aged composites were compared with the unaged composites.

\subsection{Measurements}

The flame retardancy of OMMT/FR/LGFPA6 composite was evaluated by LOI and UL-94 tests. The LOI value was surveyed on a JF-3 oxygen index meter (Jiangning, China) with the dimensions of $80 \times 10 \times 4 \mathrm{~mm}^{3}$ according to ASTM D2863-2006. The UL-94 test was performed according to ISO 1210: 1996 on a SH5300 instrument (made by HongKong Rehoboth Testing Equipment). The specimens used for this test were of the dimensions of $130 \times 13 \times 3.2 \mathrm{~mm}^{3}$. The CONE test was carried out by a FTT cone calorimeter (UK device) according to ISO 5660:2002 under a heat flux of $50 \mathrm{~kW} / \mathrm{m}^{2}$ at $25 \pm 2{ }^{\circ} \mathrm{C}$ and a relative humidity $50 \pm 5 \%$. The specimens used for this test were of the dimensions of $100 \times 100 \times 6 \mathrm{~mm}^{3}$. The experiment was stopped as soon as the flame was extinguished. Each specimen was wrapped in an aluminium foil and exposed horizontally to the heater with a standard distance of $25 \mathrm{~mm}$. The CONE values were the average of three measurements and the results were considered to be reproducible to $\pm 10 \%$.

SEM images obtained on KYKY-2800B (KYKY Technology Development, China) were used to investigate the residue chars after LOI tests and the composite surfaces for all samples with an acceleration voltage of $25 \mathrm{KV}$. All samples were recorded after gold coating surface treating. EDS (INCA 3294, Oxford Instruments, UK) was rapidly performed in SEM, operating at $10 \mathrm{kV}$ and a working distance of $10 \mathrm{~mm}$, for determining the elemental concentration changes in surfaces and char residues of different samples. The samples were surrounded with a conductive silver paint to make contact on the surface and carbon-coated in a rotary evaporator. Each sample was imaged by back-scattered electrons. The composition elements in weight and atom percentages with percent errors were analyzed by an automatic background subtraction and a ZAF correction matrix. The whole micrograph for each sample was analyzed, except for the surface of the aged OMMT/FR/LGFPA6 composite (Fig. 3(d)), where obviously presents some accumulations (under the red circle), so which acted as our selected region for the element measurement.

The thermal degradation kinetics for all composites were studied by a TGA (TA, Q-50 instruments, Co., USA), high purity grade air and nitrogen with $60 \mathrm{ml} / \mathrm{min}$ and $40 \mathrm{ml} / \mathrm{min}$ flow, respectively, the heating rates were in a range of $10-40{ }^{\circ} \mathrm{C} / \mathrm{min}[2,3 \mathrm{e}]$. The thermal stabilities for the commercially available $\mathrm{BER} / \mathrm{Sb}_{2} \mathrm{O}_{3}$ combination and all the com-

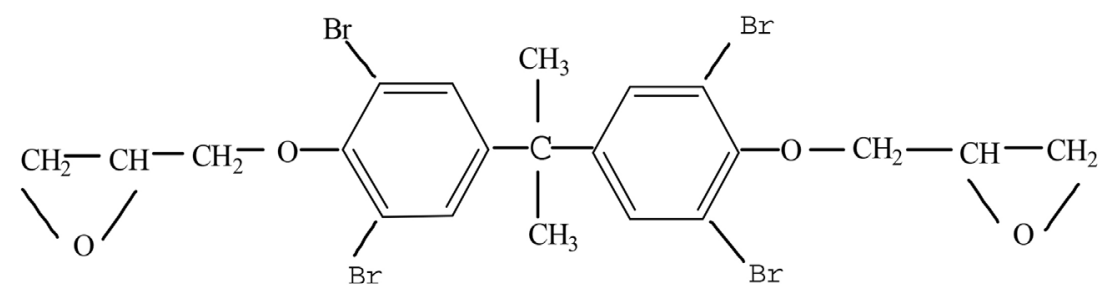

Fig. 1. Molecular structure of brominated epoxy resins. 


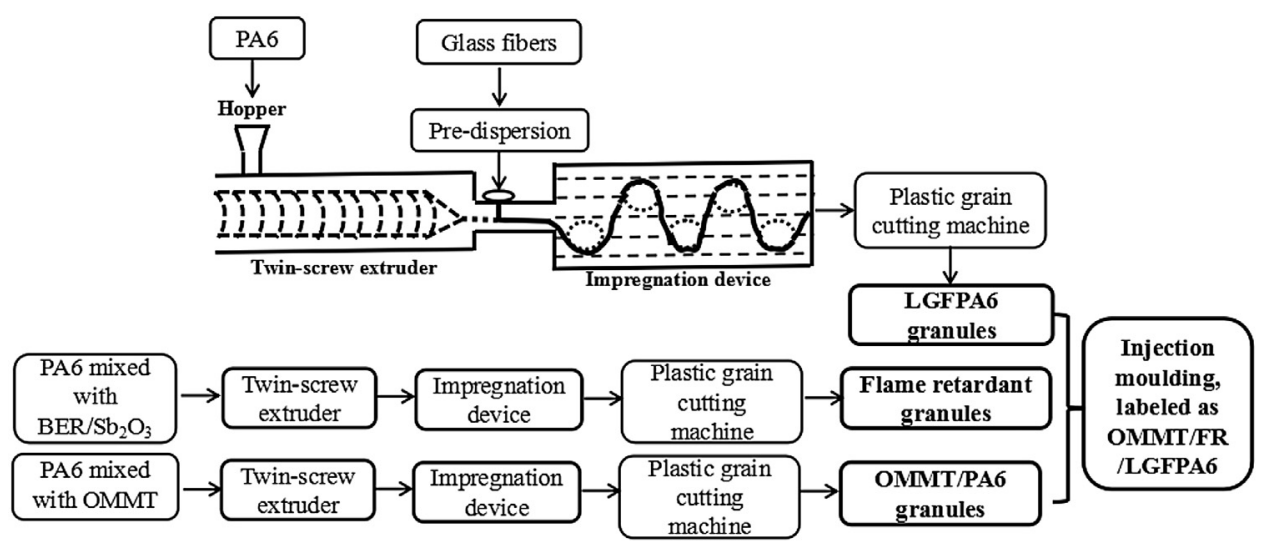

Fig. 2. The preparation processes of FR/LGFPA6 and OMMT/FR/LGFPA6 composites.

Table 1

The mass fraction of each composition for FR/LGFPA6 and OMMT/FR/LGFPA6 composites.

\begin{tabular}{llllll}
\hline Compositions & $\begin{array}{l}\text { OMMT (wt } \\
\%)\end{array}$ & $\begin{array}{l}\mathrm{BER}(\mathrm{wt} \\
\%)\end{array}$ & $\begin{array}{l}\mathrm{Sb}_{2} \mathrm{O}_{3} \text { (wt } \\
\%)\end{array}$ & $\begin{array}{l}\text { PA6 (wt } \\
\%)\end{array}$ & $\begin{array}{l}\text { GF (wt } \\
\%)\end{array}$ \\
\hline FR/LGFPA6 & - & 10 & 2.0 & 58 & 30 \\
OMMT/FR/LGFPA6 & 3 & 7.5 & 1.5 & 58 & 30 \\
\hline
\end{tabular}

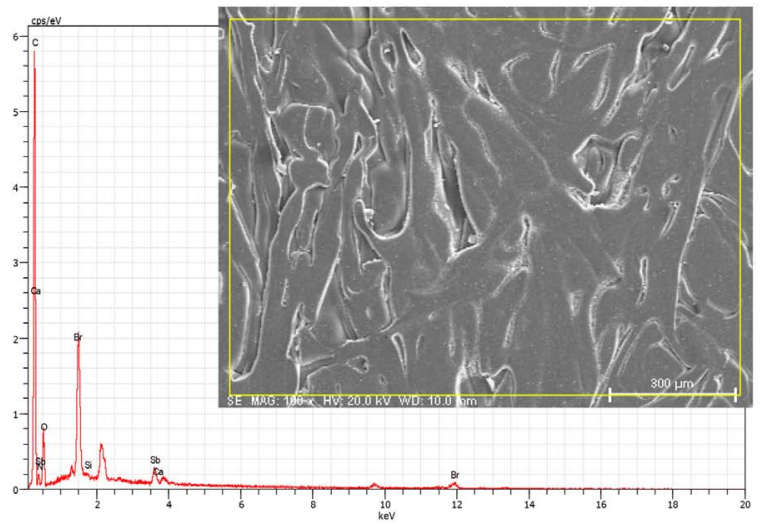

(a)

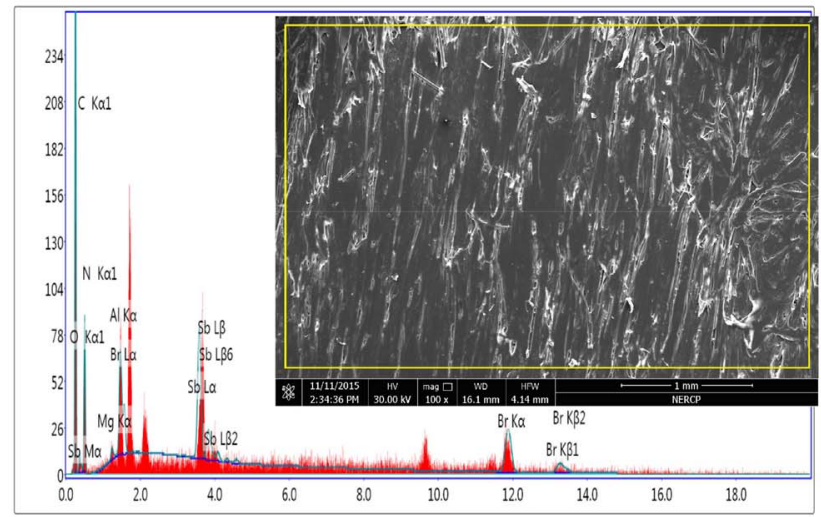

Lsec 30.00 Cints 0.000 keV Det: Octane Pro Det posites were performed at a heating rate of $20^{\circ} \mathrm{C} / \mathrm{min}$. The TGA values were the average of three measurements.

X-ray diffraction patterns (XRD) were conducted using a X'Pert (Philips, NL) X-ray diffractometer $(\lambda(\mathrm{CuK} \alpha)=1.540562 \AA)$ in configuration $\theta / \theta$ on $3 \mathrm{~mm}$-thick plates. XRD patterns were recorded in the $2 \theta$ range of $2-10^{\circ}$ with a scan rate of $2^{\circ} / \mathrm{min}$. No filtering was carried out on XRD spectra.

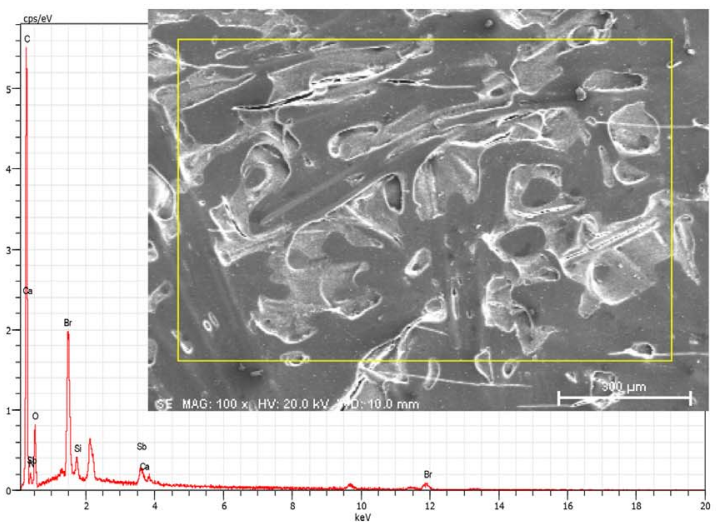

(b)

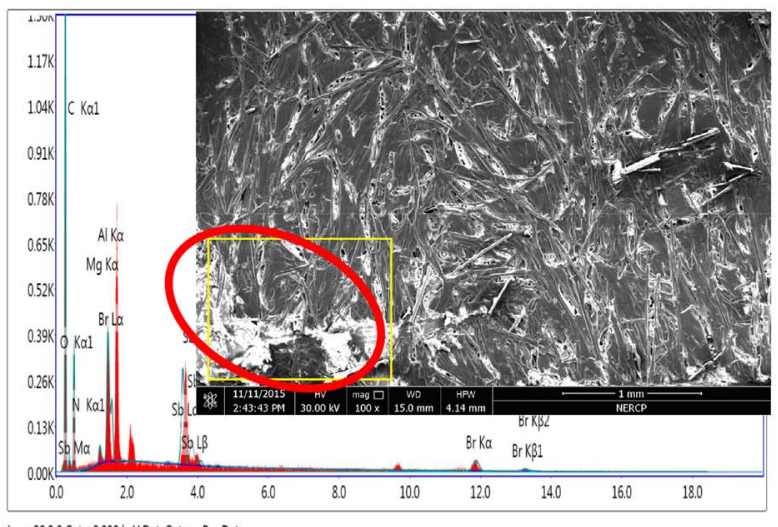

(d)

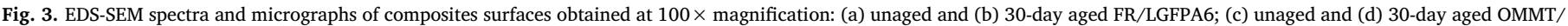
FR/LGFPA6. 
Table 2

Elemental concentrations obtained from SEM-EDS for different composite surfaces before and after aging.

\begin{tabular}{|c|c|c|c|c|c|c|c|c|c|c|c|c|}
\hline \multirow[t]{2}{*}{ Elements } & \multicolumn{3}{|c|}{ Unaged FR/LGFPA6 } & \multicolumn{3}{|c|}{$30 \mathrm{~d}$ aged FR/LGFPA6 } & \multicolumn{3}{|c|}{ Unaged OMMT/FR/LGFPA6 } & \multicolumn{3}{|c|}{$30 \mathrm{~d}$ aged OMMT/FR/LGFPA6 } \\
\hline & $\begin{array}{l}C_{\text {weight }} \\
(\%)\end{array}$ & $\begin{array}{l}\mathrm{C}_{\text {atomic }} \\
(\%)\end{array}$ & $\begin{array}{l}\text { Percent error } \\
(\%)\end{array}$ & $\begin{array}{l}C_{\text {weight }} \\
(\%)\end{array}$ & $\begin{array}{l}\mathrm{C}_{\text {atomic }} \\
(\%)\end{array}$ & $\begin{array}{l}\text { Percent error } \\
(\%)\end{array}$ & $\begin{array}{l}\mathrm{C}_{\text {weight }} \\
(\%)\end{array}$ & $\begin{array}{l}\mathrm{C}_{\text {atomic }} \\
(\%)\end{array}$ & $\begin{array}{l}\text { Percent error } \\
(\%)\end{array}$ & $\begin{array}{l}\mathrm{C}_{\text {weight }} \\
(\%)\end{array}$ & $\begin{array}{l}\mathrm{C}_{\text {atomic }} \\
(\%)\end{array}$ & $\begin{array}{l}\text { Percent error } \\
(\%)\end{array}$ \\
\hline $\mathrm{C}$ & 44.1 & 53.0 & 12.8 & 37.5 & 46.9 & 12.0 & 46.5 & 55.4 & 10.1 & 32.2 & 46.9 & 11.2 \\
\hline $\mathrm{O}$ & 35.4 & 32.3 & 10.2 & 38.4 & 37.1 & 11.4 & 30.3 & 28.9 & 12.5 & 30.5 & 32.4 & 11.4 \\
\hline $\mathrm{N}$ & 12.3 & 12.8 & 4.4 & 12.7 & 12.9 & 3.9 & 11.2 & 12.0 & 8.1 & 9.5 & 11.6 & 13.4 \\
\hline $\mathrm{Br}$ & 6.3 & 1.7 & 0.3 & 9.4 & 2.2 & 0.3 & 5.9 & 1.4 & 4.5 & 11.2 & 2.0 & 6.0 \\
\hline $\mathrm{Sb}$ & 1.8 & 0.1 & 0.1 & 1.9 & 0.3 & 0.1 & 1.3 & 0.1 & 1.9 & 3.7 & 0.5 & 2.6 \\
\hline $\mathrm{Al}$ & - & - & - & - & - & - & 3.1 & 1.5 & 5.7 & 9.5 & 4.0 & 6.3 \\
\hline $\mathrm{Mg}$ & - & - & - & - & - & - & 1.2 & 0.6 & 4.4 & 3.3 & 2.4 & 5.2 \\
\hline
\end{tabular}
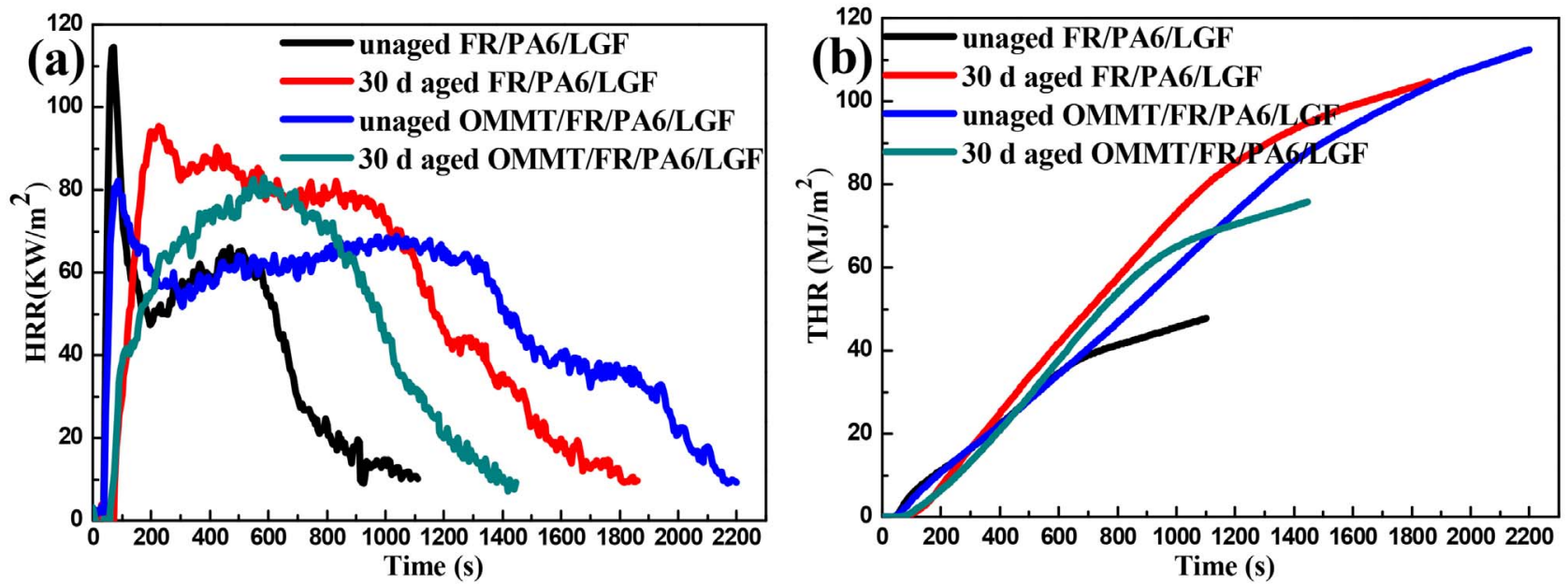

Fig. 4. The plots of (a) heat release rate and (b) total heat release as a function of combustion time for FR/LGFPA6 and OMMT/FR/LGFPA6 before and after aging.

\section{Results and discussion}

\subsection{Surface morphologies}

Fig. 3 shows the EDS-SEM micrographs of different composite surfaces, underwent 0 - and 30-day thermo-oxidative aging, obtained at magnification of $100 \times$. The content of each element is listed in Table 2 in detail. Fig. 3(a) and (c) exhibit the unaged surfaces of FR/ LGFPA6 and OMMT/FR/LGFPA6 composites, respectively. The white streaks on these surfaces are microcracks caused by the process of injection moulding. Regarding the aged FR/LGFPA6 composite (Fig. 3(b)), much more microdefects, i.e. pits and flaws, are clearly observed. While on the surface of the aged OMMT/FR/LGFPA6 composite (Fig. 3(d)), from which, only gained numerous sharp micro-scale cracks, it seems that the surface morphology of FR/LGFPA6 composite is more susceptible to aging than that of the composite filled with OMMT. The rough surface of the aged composites is caused by the degradation of PA6 maromolecules, as polyamide is a polymer quite sensitive to oxidation [6f]. This conclusion can be supported by the decreasing elemental content of carbon after aging in Table 2. Additionally, as revealed in our previous research, the intensities of the representative peaks of PA6 recorded by means of FTIR were decreased after aging $[6 \mathrm{~g}]$.

The exudation under the red circle in Fig. 3(d) was investigated by EDS, typical of the elements of the fillers are $\mathrm{Br}, \mathrm{Sb}, \mathrm{Al}$ and $\mathrm{Mg}$ (summarized in Table 2), wherein $\mathrm{Si}$ is excluded for the reason that it is difficult to distinguish between Si-rich compositions, glass fiber and clay. It can be found that the elemental content of the fillers obtained from Fig. 3(d) are higher than those for the unaged OMMT/FR/LGFPA6 composite. This change is in accordance with the trend that the content of $\mathrm{Br}$ and $\mathrm{Sb}$ elements for FR/LGFPA6 composite increases with the prolonged aging exposure time. This clearly visible exudation is recently explained by two competing assumptions: migration of the fillers or ablation of the polymers. The migration of the clay was principally supported by Lewin et al. [8b,9a-c] who ascribed this phenomenon to the generated exfoliated particles, as migration of this structure towards the surface is easier than the intercalated one. Because of the degradation of the matrix, numerous polymer segments intercalate into the clay, thereby forming the exfoliated particles characteristic of high mobility, while the intercalated particles are only arranged in the relatively large stacks [10]. Lesaffre et al. [7b] identified that FR migrates to material surface owning to the increased mobility of the polymer chain after aging. However, Colonna et al. [7] a preferred the explanation that ablation of the polymers is responsible for the phenomenon of the surface accumulation of the fillers' compositions. Noteworthily, some researchers considered both ablation of the polymers and migration occur and the different phenomena depends on the appropriate time scale [11].

Besides, it is worth noting that the microdefects in Fig. 3(b) (d) make the underlying fillers directly expose under air, accounting for the more fillers' compositions at the surface of the aged composites as well.

\subsection{Flame retardancy and burning behaviors}

CONE is an effective bench-scale test for the analysis of quantitative material burning under a continuous burning condition. The combustion behaviors of FR/LGFPA6 composite with and without OMMT, before and after aging, are plotted by heat release rate (HRR) and total heat release (THR) versus combustion time in Fig. 4 (detailed parameters are collected in Table 3).

In Fig. 4(a), concerning the FR/LGFPA6 composite before and after aging, both HRR curves are characterized by presenting a sharp pHRR at the early stage of combustion. This is one of the burning features of the GF reinforced materials, is assigned to formation of the protective 
Table 3

Results from LOI, UL-94 and CONE for different samples.

\begin{tabular}{|c|c|c|c|c|c|c|c|}
\hline Composites & TTI (s) & $\mathrm{pHRR}\left(\mathrm{KW} / \mathrm{m}^{2}\right)$ & THR $\left(\mathrm{MJ} / \mathrm{m}^{2}\right)$ & $\mathrm{TSP}\left(\mathrm{m}^{2}\right)$ & Residue (\%) & LOI (\%) & UL-94 \\
\hline Unaged FR/LGFPA6 & $26 \pm 3$ & $115 \pm 9$ & $45.6 \pm 3$ & $28.3 \pm 1.4$ & $30.2 \pm 0.2$ & 25.3 & FV-0 \\
\hline $30 \mathrm{~d}$ aged FR/LGFPA6 & $60 \pm 6$ & $95 \pm 8$ & $95.9 \pm 8$ & $19.6 \pm 0.4$ & $30.5 \pm 0.3$ & 32.3 & FV-0 \\
\hline Unaged OMMT/FR/LGFPA6 & $27 \pm 2$ & $82 \pm 7$ & $102.3 \pm 8$ & $12.4 \pm 0.5$ & $32.3 \pm 0.5$ & 25.8 & FV-0 \\
\hline $30 \mathrm{~d}$ aged OMMT/FR/LGFPA6 & $43 \pm 4$ & $83 \pm 6$ & $69.6 \pm 5$ & $13.2 \pm 0.9$ & $35.8 \pm 0.6$ & 48.5 & FV-0 \\
\hline
\end{tabular}

char and generation of the hydrogen halide [2,3]. The pHRR value of the unaged FR/LGFPA6 composite reaches $115 \pm 9 \mathrm{KW} / \mathrm{m}^{2}$ at $70 \mathrm{~s}$, after aging, decreasing to $95 \pm 8 \mathrm{KW} / \mathrm{m}^{2}$ at $225 \mathrm{~s}$ due to the higher content of the fillers' compositions at surface. So, the more hydrogen bromides would be generated to catalyze the carbonization reaction and capture the radicals with the incorporation of $\mathrm{Sb}_{2} \mathrm{O}_{3}[2,11]$.

The pHRR of the unaged FR/LGFPA6 composite is followed by a lower peak at $500 \mathrm{~s}$ (is the other specific feature of the burning behaviors of the GF reinforced materials), is assigned to damage of the aforementioned protective layers by diffusion of the volatile products $[2,3]$, while there is no new peak appearing in the HRR curve of the aged FR/LGFPA6. Furthermore, after $140 \mathrm{~s}$, the HRR values are much greater than those of the unaged composite, meanwhile, in Fig. 4(b), the THR curve of the aged composite owns greater values after $300 \mathrm{~s}$, and, in Table 3, the THR value of the aged composite $\left(95.9 \pm 8 \mathrm{MJ} / \mathrm{m}^{2}\right)$ calculated after TTI is more than twice the unaged composite $\left(45.6 \pm 3 \mathrm{MJ} / \mathrm{m}^{2}\right)$. These changes imply the protective shield formed by the aged FR/LGFPA6 composite is not as effective as the before aging one. However, aging is possible to increase the TTI of FR/LGFPA6 composite from $26 \pm 3 \mathrm{~s}$ to $60 \pm 6 \mathrm{~s}$, to reduce the total smoke production (TSP) from $28.3 \pm 1.4 \mathrm{~m}^{2}$ to $19.6 \pm 0.4 \mathrm{~m}^{2}$, to keep the pHRR at a lower value, and, to provide a high protection at the early stage of burning.

The pHRR of the unaged OMMT/FR/LGFPA6 appears at $85 \mathrm{~s}$ with a value of $82 \pm 7 \mathrm{KW} / \mathrm{m}^{2}$. After that, the curve is displayed as a plateau where the heat release is roughly constant versus time, indicating the development of a stable shield. After being ignited $(27 \pm 2 \mathrm{~s})$, the duration of combustion lasts more than $2000 \mathrm{~s}$, therefore leading to a relatively greater THR value $\left(102.3 \pm 8 \mathrm{MJ} / \mathrm{m}^{2}\right)$ than the other composites.

What is noteworthy is that, for the aged OMMT/FR/LGFPA6 composite, the occurrence of pHRR is much later than all the measured composites, appearing at $585 \mathrm{~s}$ with a value of $83 \pm 6 \mathrm{KW} / \mathrm{m}^{2}$. Additionally, whose HRR and THR curves are appreciably lower than those of the aged FR/LGFPA6 composite almost over the whole combustion, thus, the obtained THR value $\left(69.6 \pm 5 \mathrm{MJ} / \mathrm{m}^{2}\right)$ is relatively low. Similarly, aging is possible to increase the TTI of OMMT/FR/LGFPA6 composite from $27 \pm 2 \mathrm{~s}$ to $43 \pm 4 \mathrm{~s}$, to render it less flammable at the preliminary and late stages of burning, respectively, and, to have less influence on the TSP (from $12.4 \pm 0.5 \mathrm{~m}^{2}$ to $13.2 \pm 0.9 \mathrm{~m}^{2}$ ). It can be found that even if aged FR/LGFPA6 composite becomes more flammable after $140 \mathrm{~s}$ of combustion, while substitution of a certain content of BER-Sb ${ }_{2} \mathrm{O}_{3}$ with OMMT markedly offsets this problem.

Fig. 5 shows the digital morphologies of the residues after CONE. After this sustaining combustion test, there is almost no char left in both Fig. 5(a) and (b). The white substances are glass fibers, their final weight fluctuates within 30-31\%. With respect to OMMT/FR/LGFPA6 composite, a thin inorganic-film covers the whole residue surfaces in both Fig. 5(c) and (d), for which the residue amount is equal to $32.4 \pm 0.5 \%$ and $35.8 \pm 0.6 \%$, respectively. In addition, in Fig. 5(d), a few chars can be found, implying that the residues of the aged OMMT/FR/LGFPA6 composite mainly consist of silicate layers and chars.

The residues of the composites before and after aging, collected after LOI tests, are presented in Fig. 6. There is only a few sparse chars adhering on the GF surfaces of the unaged FR/LGFPA6 composite (Fig. 6(a)). This phenomenon can be attributed to the "candle-wick effect", that is, for one thing, much more heat would be conducted into underlying matrix compared to the neat polymer at the same burning time, because GF $(1.1-1.5 \mathrm{~W} /(\mathrm{m} \cdot \mathrm{K})$ [13]) has a greater thermal conductivity than PA6 $(0.23-0.29 \mathrm{~W} /(\mathrm{m} \cdot \mathrm{K})[13 \mathrm{a}, 14])$. For another, the ablation of matrix and combustible products as fuels would be transmitted into burning zone along the GFs. Hence, the combustion would be more severe, and the LOI value is only $25.3 \%$ for the unaged FR/LGFPA6 composite.

It appears that the residue morphology of the aged FR/LGFPA6 composite (Fig. 6(b), with a LOI value of $32.3 \%$ ) is basically consistent with the unaged OMMT/FR/LGFPA6 composite (Fig. 6(c)): some residue chars can be obtained. However, the LOI value of the unaged OMMT/FR/LGFPA6 composite has not an appreciable increase in comparison with the unaged FR/LGFPA6 composite, only $25.8 \%$. In Fig. 6 (d), much denser chars are apparently observable for the aged OMMT/FR/LGFPA6 composite, accompanied by a greatly increased LOI value, $48.5 \%$.

Remarkably, all composites in the UL-94 tests, regardless of their forms (aged or unaged, with or without OMMT), their burning ratings all meet the optimal V-0 rating, and none of them exhibits any dripping phenomenon, since the disordered dispersion of glass fibers in matrix is the counterpart of the bracket to hold up the melt dripping [2].

It is worth mentioning that the aged FR/LGFPA6 composite performs well in the short period of burning tests, i.e. LOI and UL-94, the combustion duration of both tests are virtually less than $300 \mathrm{~s}$, which is the point of demarcation for the THR curves of the unaged and aged FR/LGFPA6 composites (Fig. 4(b)). Before this, the phenomena that the higher content of the flame retardants' compositions and the microcracks at surface are beneficial to obtain the favorable LOI value and the relatively thick residue chars. After this, the aged FR/LGFPA6 composite becomes more flammable owning to the poor quality of char layers and the generation of inflammable polymer segments. As for OMMT/FR/LGFPA6 composite, whose flame retardancy are also heavily improved after aging. Except the same explanations that, for one thing, the combustion duration of LOI and UL-94 tests is less than $460 \mathrm{~s}$ (achieved from Fig. 4 (b)), for another, the surface accumulation of fillers' compositions and the surface microcracks contribute to the barrier effect. This phenomenon can also be explained by the formation of more strongly acidic proton sites caused by the decomposition of clay during aging, which plays a significant role in charring [16].

The X-Ray diffractograms of OMMT and aged OMMT/FR/LGFPA6 composite before and after UL-94 tests are shown in Fig. 7. OMMT has a characteristic signal at $2 \theta=4.32^{\circ}$ that corresponds to an interlayer distance of $2.04 \mathrm{~nm}$. Before UL-94 test, the interlayer distance of the aged OMMT/FR/LGFPA6 composite shifts to $2 \theta=4.12^{\circ}(2.14 \mathrm{~nm})$, indicating the formation of the intercalated structure for the clay lamellas, by means of intercalation of the polymer chains. However, no clear characteristic signal can be found for the aged OMMT/FR/ LGFPA6 composite after UL-94 test, indicating the formation of the exfoliated lamellas in the char residues, by means of ablative reassembling of the silicate layers during combustion. From the summarized data in Table 4, we are aware that the content of $\mathrm{Al}$ and $\mathrm{Mg}$ obtained from the residues of the aged OMMT/FR/LGFPA6 composite after UL94 test are higher than those for the unaged composite. These results 


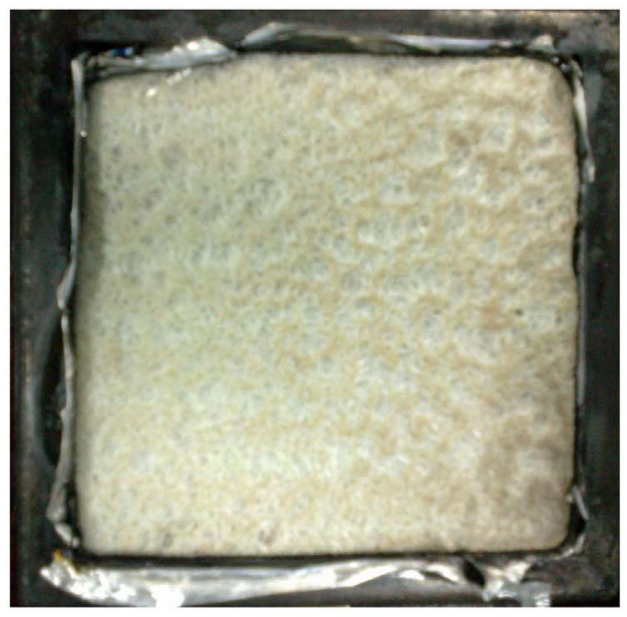

(a)

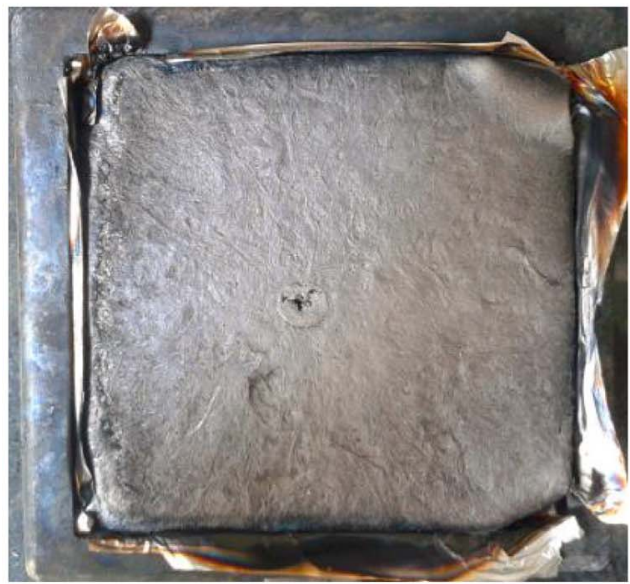

(c)

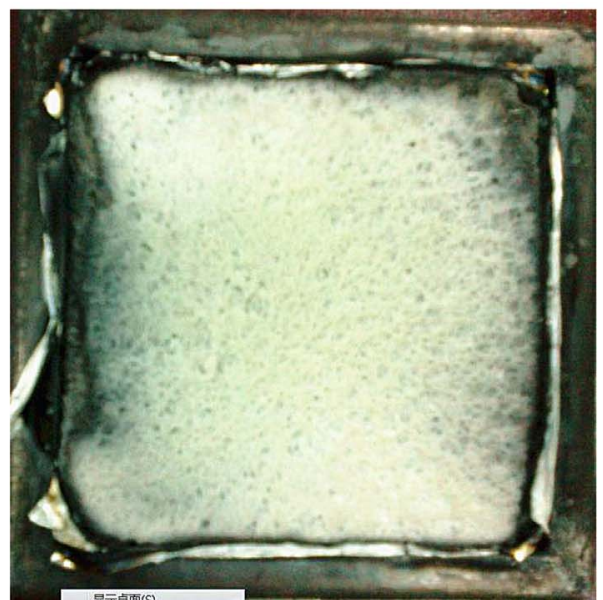

(b)

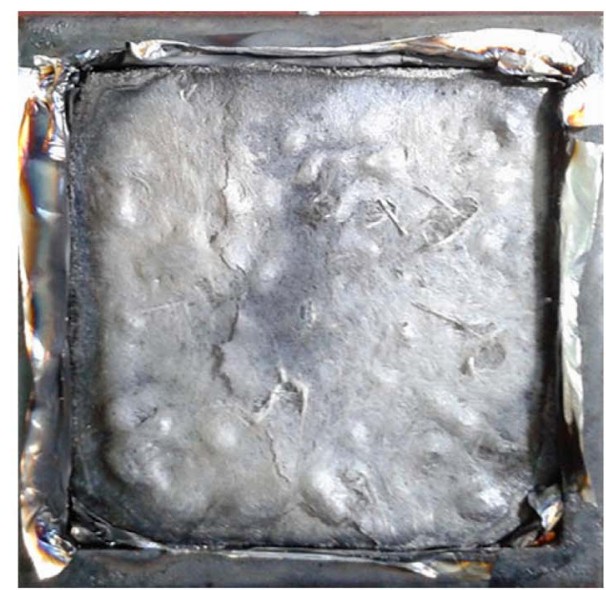

(d)

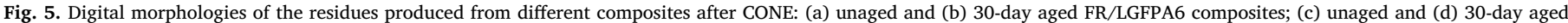
OMMT/FR/LGFPA6 composites.

demonstrate that combustion prompts more clay lamellas to intercalate into the chars of the aged composite, so that a more protective multilayered structure would be formed during the combustion of the aged composite. After aging, the higher mobility of clay lamellas could be attributed to either the numerous aging-provoked degraded segments intercalate into the lamellas, or, the decreased size of the gallery of the internal clay layer caused by the aging-provoked disaggregation/ de-crystallization or melting of the long chain tails of the surfactants [7b,9a,17]. Therefore, except for the above-mentioned causes, the formation of more multilayers also accounts for the improved flame retardancy of the aged OMMT/FR/LGFPA6 composite, by obstructing the further penetration of heat emission and limiting the oxygen diffusion and degradation products $[8 \mathrm{a}, 18]$.

\subsection{Thermal stability}

The thermal decomposition performed in oxidative atmosphere of pristine OMMT is shown in Fig. 8(a) and (b). The liberation of free absorbed water, residing between montmorillonite crystallites, acts as the dominant weight loss for OMMT until $150{ }^{\circ} \mathrm{C}$. Beyond this, the main degradation can be divided into three regions. The loss of an unconfined fraction of alkylammonium halide surfactant corresponds to the first degradation event: $150-350{ }^{\circ} \mathrm{C}$ (with a maximum decomposition rate $\mathrm{T}_{\mathrm{p}}$ at $297^{\circ} \mathrm{C}$ ) [11]. The second and third regions of degradation take place in a temperature range of $350-450$ and $450-650{ }^{\circ} \mathrm{C}$, with a
$\mathrm{T}_{\mathrm{p}}$ at 422 and $568^{\circ} \mathrm{C}$, respectively, referring to the evolution of organic substance and structural water $[11,12]$. Considering that specimen preparation was carried out within $205-280{ }^{\circ} \mathrm{C}$ and that the weight loss of OMMT was about $8 \%$ before $280^{\circ} \mathrm{C}$, the indication is that during the processes of extrusion and injection molding, a release of free absorbed water and a loss of unconfined organic fraction would take place in OMMT.

Fig. 8(c) and (d) shows the typical TGA and differential thermogravimetry (DTG) curves of the neat $\mathrm{BER} / \mathrm{Sb}_{2} \mathrm{O}_{3}$ at $10{ }^{\circ} \mathrm{C} / \mathrm{min}, 20^{\circ} \mathrm{C}$ / min and $30^{\circ} \mathrm{C} / \mathrm{min}$, respectively. All the curves in Fig. 8(c) recorded at different heating rates are characterized by a drastic change in slope of the curve, ascribable to the interaction between BER and $\mathrm{Sb}_{2} \mathrm{O}_{3}$, subsequently in a higher temperature range, followed by a pretty small change in slope of the curve, which correlates with the degradation behavior of the resultant of oxibromide, $\mathrm{SbOBr}$, that would be further decomposed into $\mathrm{SbBr}_{3}$ in a broad temperature range [6a,b]. Fig. 8(d) presents the $T_{p}$ shifts to a high temperature range with the increase of heating rate.

Fig. 8(e) and (f) display the unaged FR/LGFPA6 and OMMT/FR/ LGFPA6 composites degrade rapidly between 320 and $450{ }^{\circ} \mathrm{C}$ and have two degradation peaks. The first peak is linked to the decomposition of fillers, the other one corresponds to the rupture of PA6 main-chain backbone. After aging, the degradation rate maxima for FR/LGFPA6 composite drop from $1.16\left(364^{\circ} \mathrm{C}\right)$ and $0.96\left(398{ }^{\circ} \mathrm{C}\right)$ to $0.77 \% /{ }^{\circ} \mathrm{C}$ $\left(366^{\circ} \mathrm{C}\right)$, suggestive of a decreased thermal stability, due to the 


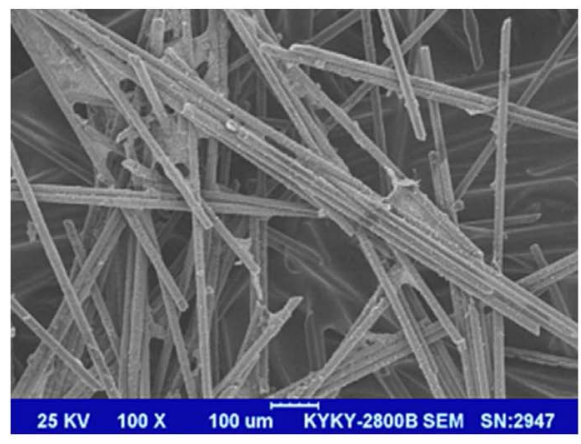

(a)

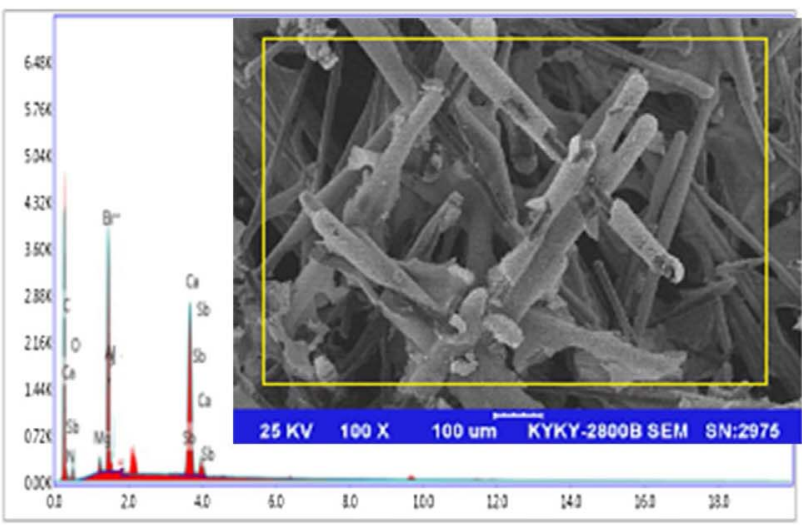

(c)

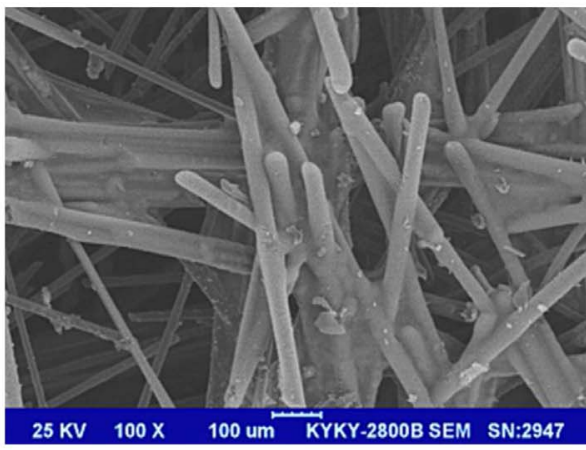

(b)



(d)

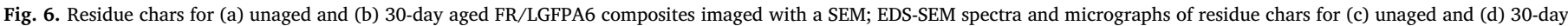
aged OMMT/FR/LGFPA6 composites. All micrographs are obtained after LOI and at $100 \times$ magnification.

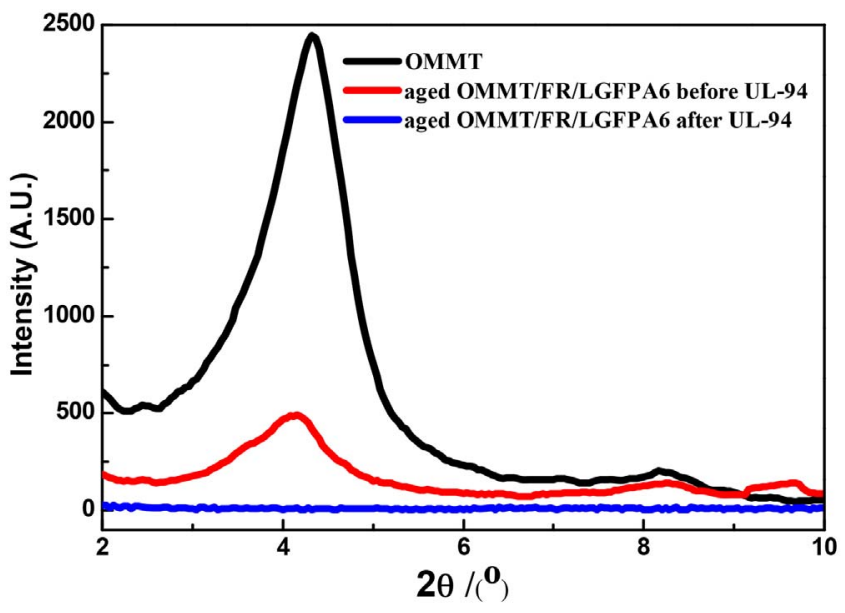

Fig. 7. XRD patterns of OMMT, aged OMMT/FR/LGFPA6 composite before and after UL94 tests.

degradation of matrix during aging. At the end of degradation, they remain a quantity of $30.3 \%$ (unaged) and $30.7 \%$ (aged) residues, respectively. As for OMMT/FR/LGFPA6 composite, the degradation rate maxima decline from $1.00\left(367^{\circ} \mathrm{C}\right)$ and $1.21\left(397{ }^{\circ} \mathrm{C}\right)$ to $0.85 \% /{ }^{\circ} \mathrm{C}$ $\left(404^{\circ} \mathrm{C}\right)$, while an increased thermal stability can be found. The final residues reach 32.0 and $35.1 \%$ for the unaged and aged composite, respectively.

Remarkably, comparisons of the final residues obtained from both CONE and TGA tests show that, nearly no change is found for FR/
Table 4

Elemental concentrations obtained from the residue chars of unaged and aged OMMT/ FR/LGFPA6 composites after UL-94 tests.

\begin{tabular}{|c|c|c|c|c|c|c|c|c|}
\hline Elements & & $\mathrm{C}$ & $\mathrm{O}$ & $\mathrm{N}$ & $\mathrm{Br}$ & $\mathrm{Sb}$ & $\mathrm{Al}$ & $\mathrm{Mg}$ \\
\hline \multirow{3}{*}{$\begin{array}{l}\text { Unaged OMMT/FR/ } \\
\text { LGFPA6 }\end{array}$} & $\mathrm{C}_{\text {weight }}(\%)$ & 72.8 & 5.3 & 2.6 & 3.2 & 1.0 & 10.3 & 4.4 \\
\hline & $\mathrm{C}_{\text {atomic }}(\%)$ & 82.6 & 3.5 & 2.5 & 0.9 & 0.1 & 7.7 & 2.6 \\
\hline & $\begin{array}{l}\text { Percent error } \\
(\%)\end{array}$ & 7.8 & 13.5 & 10.0 & 6.4 & 7.5 & 9.7 & 8.0 \\
\hline \multirow{3}{*}{$\begin{array}{c}\text { Aged } 30 \mathrm{~d} \text { OMMT/ } \\
\text { FR/LGFPA6 }\end{array}$} & $\mathrm{C}_{\text {weight }}(\%)$ & 64.2 & 7.7 & 3.6 & 2.8 & 0.8 & 14.2 & 8.5 \\
\hline & $\mathrm{C}_{\text {atomic }}(\%)$ & 72.5 & 5.9 & 3.1 & 0.8 & 0.1 & 11.2 & 6.3 \\
\hline & $\begin{array}{l}\text { Percent error } \\
(\%)\end{array}$ & 5.5 & 11.5 & 15.8 & 8.1 & 9.8 & 7.4 & 6.9 \\
\hline
\end{tabular}

LGFPA6 composite before and after aging, while a slight increase is found for OMMT/FR/LGFPA6 composite after aging.

\subsection{Degradation kinetics}

In order to further research the mechanism of physical and chemical processes that occur during the degradation of the polymeric material, non-isothermal pyrolysis kinetics are employed thereinafter using TGA at controlled heating rates. Generally, most methods of thermogravimetric kinetic analysis begin with the well-known Arrhenius expression

$\kappa=A \exp (-E / R T)$

and a rate expression

$\mathrm{d} \alpha / d T=\kappa f(\alpha)$. 

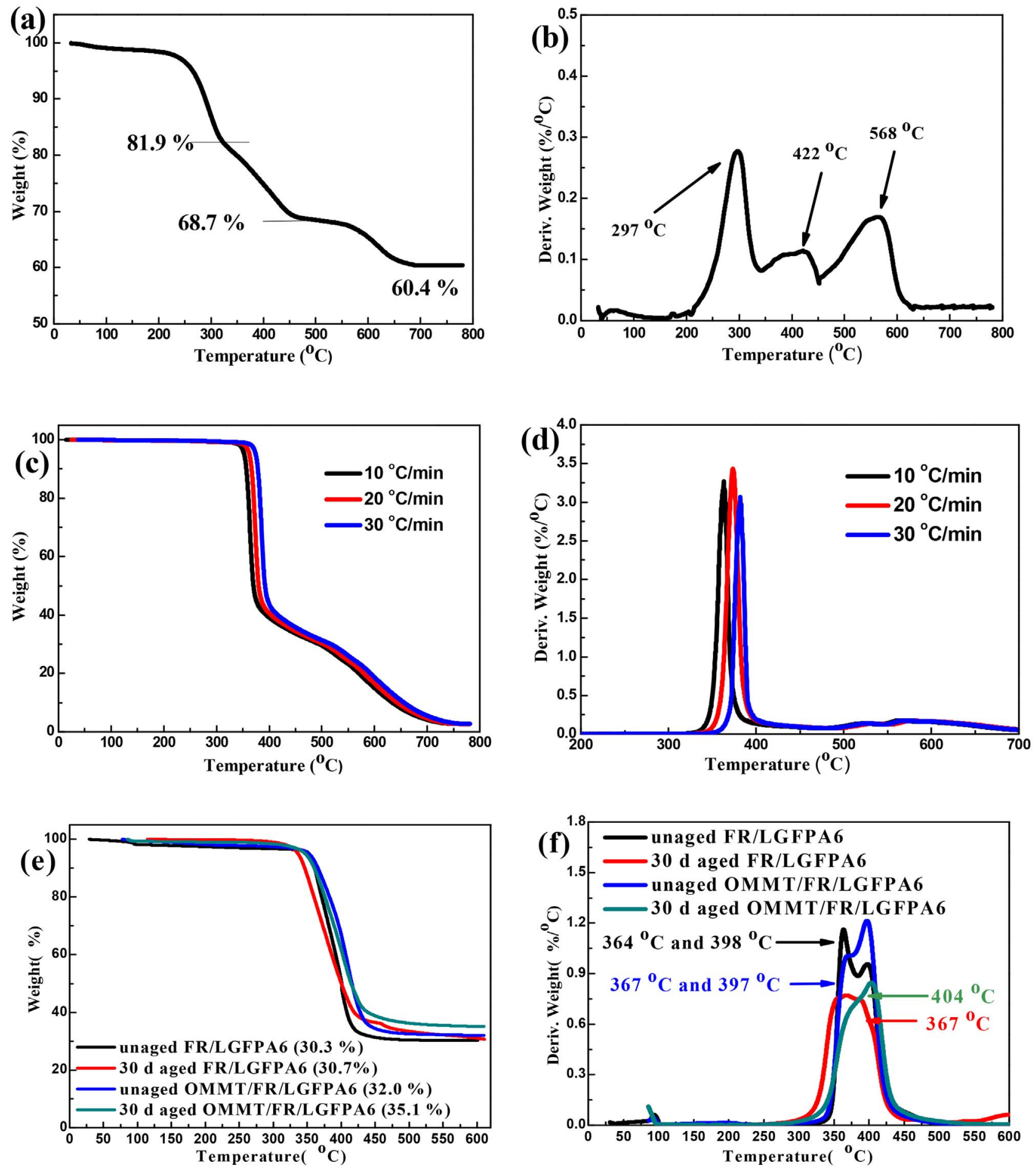

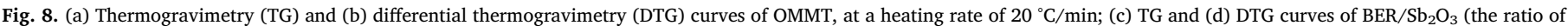

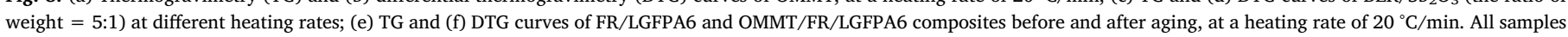
performed in oxygen.

Where $\kappa$ in Eq. (1) is a rate constant characterized by temperature dependence. The $\alpha$ in Eq. (2) is the degree of the conversion of the solid reactant, and the expression $f(\alpha)$ is the so-called kinetic function that depends on the reaction mechanism. Then substitution of Eq. (1) in Eq. (2) gives:

$\mathrm{d} \alpha / d t=A \exp (-E / R T) f(\alpha)$.

For a constant heating rate, $\beta=d T / d t$
Substitution of Eq. (4) in Eq. (3) gives:

$\mathrm{d} \alpha / d T=\frac{A}{\beta} \exp (-E / R T) f(\alpha)$

$\ln (\beta d \alpha / d T)=\ln [A f(\alpha)]-E / R T$

$\mathrm{g}(\alpha)=\int_{0}^{\alpha}\left[\frac{1}{(1-\alpha)^{n}}\right] d \alpha=\frac{A}{\beta} \int_{T_{0}}^{T} \exp \left[\frac{-E_{a}}{R T}\right] d T$ 
Table 5

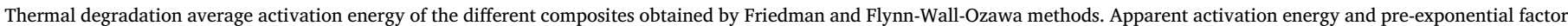
A obtained by Coats-Redfern method at a heating rate of $10^{\circ} \mathrm{C} / \mathrm{min}$.

\begin{tabular}{|c|c|c|c|c|c|}
\hline \multirow[t]{2}{*}{ Samples } & & \multicolumn{2}{|l|}{ FR/LGFPA6 } & \multicolumn{2}{|l|}{ OMMT/FR/LGFPA6 } \\
\hline & & unaged & $30 \mathrm{~d}$ aged & unaged & $30 \mathrm{~d}$ aged \\
\hline Friedman method & $\begin{array}{c}\mathrm{E}_{\mathrm{a}}(\mathrm{KJ} / \mathrm{mol}) \\
\mathrm{R}^{2}\end{array}$ & $\begin{array}{l}183.9 \pm 5.3 \\
0.9585 \pm 0.08\end{array}$ & $\begin{array}{l}177.3 \pm 4.9 \\
0.9691 \pm 0.07\end{array}$ & $\begin{array}{l}118.0 \pm 2.7 \\
0.9540 \pm 0.05\end{array}$ & $\begin{array}{l}128.8 \pm 3.5 \\
0.9729 \pm 0.04\end{array}$ \\
\hline Flynn-Wall-Ozawa method & $\begin{array}{c}\mathrm{E}_{\mathrm{a}}(\mathrm{KJ} / \mathrm{mol}) \\
\mathrm{R}^{2}\end{array}$ & $\begin{array}{l}183.3 \pm 6.1 \\
0.9613 \pm 0.10\end{array}$ & $\begin{array}{l}150.6 \pm 4.9 \\
0.8555 \pm 0.09\end{array}$ & $\begin{array}{l}110.1 \pm 1.9 \\
0.9045 \pm 0.04\end{array}$ & $\begin{array}{l}137.8 \pm 2.9 \\
0.9545 \pm 0.06\end{array}$ \\
\hline Coats-Redfern method & $\begin{array}{c}\mathrm{E}_{\mathrm{a}}(\mathrm{KJ} / \mathrm{mol}) \\
\mathrm{R}^{2} \\
\mathrm{~A}\end{array}$ & $\begin{array}{l}183.7 \pm 1.8 \\
0.9679 \pm 0.02 \\
(2.59 \pm 0.76) \times 10^{16}\end{array}$ & $\begin{array}{l}166.4 \pm 2.8 \\
0.9065 \pm 0.02 \\
(1.09 \pm 0.45) \times 10^{15}\end{array}$ & $\begin{array}{l}124.7 \pm 2.7 \\
0.9288 \pm 0.03 \\
(2.56 \pm 0.89) \times 10^{11}\end{array}$ & $\begin{array}{l}133.0 \pm 2.0 \\
0.9474 \pm 0.03 \\
(1.05 \pm 1.54) \times 10^{12}\end{array}$ \\
\hline
\end{tabular}

$\log \beta=\log [A E / R g(\alpha)]-2.315-0.4567 E / R T$

(8)

Which is normally the elementary equation for the kinetic analysis of a solid material. Herein, $\mathrm{E}$ is the activation energy of the reaction, A is the frequency factor, $\mathrm{T}$ is the reaction temperature, and $\mathrm{R}$ is the gas constant.

Friedman (Eq. (6)) and Flynn-Wall-Ozawa (Eq. (8)) methods are firstly employed to analyze the degradation kinetics of materials, because they are the viable approaches to analyze the whole degradation stages and are independent of any thermal degradation mechanism [15]. Typically the latter one was developed for addressing the integral of Eq. (7) in a condition where $f(\alpha)=(1-\alpha)^{\mathrm{n}}$ upon the Doyle approximation [15b]. Because of the $30 \mathrm{wt} \%$ loading of glass fibers, so in this case, the $\alpha$ varies in a range of $0.1-0.6$. The Arrhenius activation energy $\mathrm{E}$ can be obtained by the slope of the linear fitting of $\ln (\beta \mathrm{d} \alpha / \mathrm{dT}) v s .1 / \mathrm{T}$
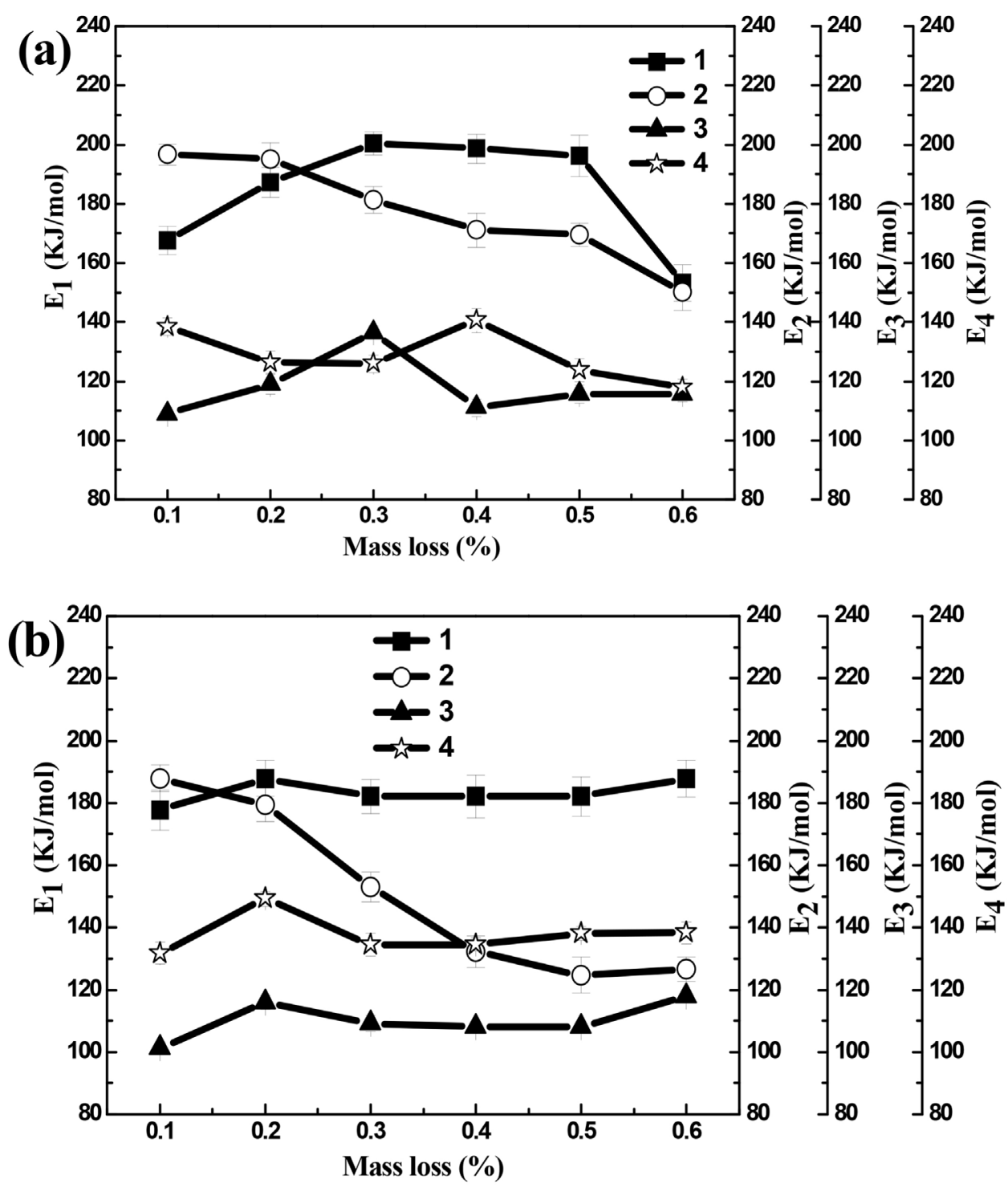

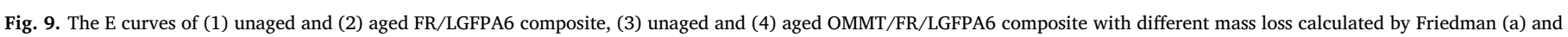
Flynn-Wall-Ozawa (b) methods. 
and $\log \beta$ vs. $1 / \mathrm{T}$, respectively. The different temperatures corresponding to the degradation temperature for the different degree of the conversion of the solid material. Fig. 8 displays the calculated $\mathrm{E}$ at different $\alpha$ and the average values $\mathrm{E}_{\mathrm{a}}$ are given in Table 5 .

It can be found that the average $E_{a}$ value of FR/LGFPA6 composite has a minor decrease of $3.6 \%$ after aging obtained by the Friedman method, while a moderate decrease of $17.8 \%$ is observed by the calculation of Flynn-Wall-Ozawa method. It is clear that the average $\mathrm{E}_{\mathrm{a}}$ value of OMMT/FR/LGFPA6 composite calculated using the two methods follows the same trend, increasing by $9.2 \%$ and $25.2 \%$ after aging, respectively.

In Fig. 9(a), before $\alpha=20 \%$, both aged FR/LGFPA6 and OMMT/ FR/LGFPA6 composites present a higher $\mathrm{E}$ value than that of the corresponding unaged composites. After this, a reversed trend is shown by FR/LGFPA6 composite. Except for $\alpha=30 \%$, OMMT/FR/LGFPA6 composite still remains the same trend. In Fig. 9(b), relative to the unaged FR/LGFPA6 composite, aged FR/LGFPA6 composite exhibits a greater E value only when meeting $10 \%$ partial mass loss. Whereas, aged OMMT/FR/LGFPA6 composite has a higher $\mathrm{E}$ value than the unaged composite at any degradation stage.

$\ln \left[g(\alpha) / T^{2}\right]=\ln [A R / \beta E]-E / R T$

To investigate the effects of aging on the thermal degradation mechanisms of composites, Coats-Redfern method (Eq. (9)) is chosen. This method uses an asymptotic approximation for the resolution at different degradation degrees. Seventeen forms of $g(\alpha)$ collected in Table S1 are used for enunciating the mechanism of thermal decomposition. Table 5 summarizes the activation energies and correlations obtained from the slope of $\ln \left[g(\alpha) / T^{2}\right] v s .1 / T$, as well as the preexponential factor A calculated from the intercept of the plots of Eq. (9).

Analysis of Table 5 shows that the activation energies calculated by Coats-Redfern method are in better agreement with those obtained using Friedman and Flynn-Wall-Ozawa methods, especially for the value of unaged FR/LGFPA6 composite. The activation energy of FR/ LGFPA6 composite decreases by $9.4 \%$ after aging, while increases by $8 \%$ for OMMT/FR/LGFPA6 composite. It can be stated that the solidstate decomposition mechanisms for the FR/LGFPA6 composite before and after aging correspond to boundary reaction of phase and nucleation and nucleus growth, respectively with integral forms $g(\alpha)=\alpha^{3 / 2}$ and $g(\alpha)=[-\ln (1-\alpha)]^{2}$. The mechanism function with integral form $g$ $(\alpha)=-\ln (1-\alpha)$ belongs to the mechanism of nucleation and nucleus growth, and is the most probable describing function for the unaged OMMT/FR/LGFPA6 composite. Similarly the aged OMMT/FR/LGFPA6 composite follows the mechanism of boundary reaction of phase as well, with integral form $g(\alpha)=\alpha^{3 / 2}$. The above results analyzed by Friedman, Flynn-Wall-Ozawa and Coats-Redfern methods fully support the causes for the changes in the flame retardancy and the flammability of OMMT/FR/LGFPA6 composite after aging.

\section{Conclusions}

This paper addressed studies on the aging properties of LGFPA6 composite formulated with clay-brominated epoxy resins-antimony, compared with that without clay, mainly focusing on the aspects of flammability, flame retardany and thermal kinetics.

The results showed in this study prove that, for both composites, aging for 30 days is possible to increase the time to ignition, keep the pHRR at a lower value, promote the LOI value than that measured for the unaged composites, and to maintain the optimal burning rating, on the premise that aging them at an appropriate temperature. This study confirms $160{ }^{\circ} \mathrm{C}$ to be a feasible given temperature. In addition, substitution of a certain content of $\mathrm{BER}-\mathrm{Sb}_{2} \mathrm{O}_{3}$ with OMMT positively improves not only the combustion behavior but also the thermal stability for the aged FR/LGFPA6 composite.

Remarkably, the apparent activation energies calculated by the Friedman, Flynn-Wall-Ozawa and Coats-Redfern methods comprehen- sively support the beneficial role of OMMT in resisting the impact of thermo-oxidative aging. Moreover, the change in activation energy with aging time obtained from the former two methods which are independent of degradation mechanism is in agreement with that analyzed by the latter method. Correspondingly the most probable mechanism functions with integral form can be expressed by $g(\alpha)$ $=\alpha^{3 / 2}$ and $g(\alpha)=[-\ln (1-\alpha)]^{2}$ for FR/LGFPA6 composite before and after aging, $g(\alpha)=-\ln (1-\alpha)$ and $g(\alpha)=\alpha^{3 / 2}$ for OMMT/FR/LGFPA6 composite before and after aging, respectively.

\section{Conflicts of interest}

The authors declare no conflict of interest.

\section{Acknowledgments}

Jianbing Guo is grateful for the financial supported by Guizhou Province High-level Innovative Talents Training Projects (contract grant number: 4039/2015, 5667/2016). Xiaoling Zuo gratefully acknowledges the China Scholarship Council (contract grant number: 201406670002) for the financial support.

\section{Appendix A. Supplementary data}

Supplementary data associated with this article can be found, in the online version, at http://dx.doi.org/10.1016/j.tca.2017.04.001.

\section{References}

[1] A. Casu, G. Camino, M. De Giorgi, D. Flath, D. Laudi, V. Morone, Effect of glass fibres and fire retardant on the combustion behavior of composites, glass fibres-poly (butylene terephthalate), Fire Mater. 22 (1998) 7-14.

[2] X.L. Zuo, H.J. Shao, D.H. Zhang, Z. Hao, J.B. Guo, Effects of thermo-oxidative aging on the flammability and thermo-oxidative degradation kinetics of tris(tribromophenyl) cyanurate flame retardant LGFPA6 composites, Polym. Degrad. Stab. 98 (2013) 2774-2783.

[3] (a) Y. Liu, Q. Wang, Melamine cyanurate-microencapsulated red phosphorus flame retardant unreinforced and glass fiber reinforced polyamide 66, Polym. Degrad. Stab. 91 (2006) 3103-3109;

(b) C.S. Zhao, F.L. Huang, W.C. Xiong, Y.Z. Wang, A novel halogen-free flame retardant for glass-fiber-reinforced poly(ethylene terephthalate), Polym. Degrad. Stab. 93 (2008) 1188-1193;

(c) Y.H. Chen, Q. Wang, Preparation, properties and characterizations of halogen free nitrogen ephosphorous flame-retarded glass fiber reinforced polyamide 6 composite, Polym. Degrad. Stab. 91 (2006) 2003-2013;

(d) M.R. Ricciardi, V. Antonucci, M. Giordano, M. Zarrelli, Thermal decomposition and fire behavior of glass fiber-reinforced polyester resin composites containing phosphate-based fire-retardant additives, J. Fire. Sci. 30 (2012) 318-330; (e) W.D. He, N. Liu, X.L. Chen, J.B. Guo, T. Wei, The influence of hygrothermal ageing on the mechanical properties and thermal degradation kinetics of long glass fi bre reinforced polyamide 6 composites filled with sepiolite, RSC Adv. 6 (2016) 36689.

[4] (a) J.H. Mao, D.Y. Gui, Study on epoxy molding compounds modified by novel phosphorus-containing flame retardant and OMMT, 7th International Conference on Electronics Packaging Technology, Shanghai, August, 2006, 2006, pp. 26-29; (b) J. Feng, J.W. Hao, J.X. Du, R.J. Yang, Effects of organoclay modifiers on the flammability, thermal and mechanical properties of polycarbonate nanocomposites filled with a phosphate and organoclays, Polym. Degrad. Stab. 97 (2012) 108-117; (c) N.A. Isitman, H.O. Gunduz, C. Kaynak, Nanoclay synergy in flame retarded/ glass fibre reinforced polyamide 6, Polym. Degrad. Stab. 94 (2009) 2241-2250.

[5] A. Zotti, A. Borriello, M. Ricciardi, V. Antonucci, M. Giordano, M. Zarrelli, Effects of sepiolite clay on degradation and fire behaviour of a bisphenol A-based epoxy, Compos. Part B-Eng. 73 (2015) 139-148.

[6] (a) R.L. Clough, Aging effects on fire-retardant additives in polymers, J. Polym. Sci. Polym. Chem. 21 (1983) 767-780;

(b) R.L. Clough, Aging effects on fire-retardant additives in organic materials for nuclear plant applications, (1982) NUREG/CR-2868 SAND82-0485 RV;

(c) X. Almeras, M. Le Bras, Artificial weathering and recycling effect on intumescent polypropylene based blends, J. Fire. Sci. 22 (2004) 143-161;

(d) U. Braun, V. Wachtendorf, A. Geburtig, H. Barh, B. Schartel, Weathering resistance of halogen-free flame retardance in thermoplastics, Polym. Degrad. Stab. 95 (2010) 2421-2429;

(e) H. Vahabi, R. Sonnier, L. Ferry, Effects of ageing on the fire behaviour of flameretarded polymers: a review, Polym. Int. 64 (2015) 313-328;

(f) Y. Shu, L. Ye, T. Yang, Study on the Long-term Thermal-oxidative Aging Behavior of Polyamide 6, J. Appl. Polym. Sci. 110 (2008) 945-957; (g) X.L. Zuo, K.Z. Zhang, Y. Lei, S.H. Qin, Z. Hao, J.B. Guo, Influence of thermo- 
oxidative aging on the static and dynamic mechanical properties of long-glass-fiber reinforced polyamide 6 composites, J. Appl. Polym. Sci. 131 (2014) 39594.

[7] (a) S. Colonna, F. Cuttica, A. Frache, Aging of EVA/organically modified clay: aing of EVA/organically modified clay: effect on dispersion, distribution and combustion begavior, Polym. Degrad. Stab. 107 (2014) 184-187;

(b) N. Lesaffre, S. Bellayer, G. Fontaine, M. Jimenez, S. Bourbigot, Revealing the impact of ageing on a flame retarded PLA, Polym. Degrad. Stab. 127 (2016) 88-97.

[8] (a) M. Zanetti, T. Kashiwagi, L. Falqui, G. Camino, Cone calorimeter combustion and gasification studies of polymer layered silicate nanocomposites, Chem. Mater. 14 (2002) 881-887;

(b) Y. Tang, M. Lewin, E.M. Pearce, Effects of annealing on the migration behavior of PA6/clay nanocomposites, Macromol. Rapid. Comm. 27 (2006) 1545-1549; (c) M. Lewin, Y. Tang, Oxidation-migration cycle in polypropylene-based nanocomposites, Macromolecules 41 (2008) 13-17.

[9] (a) M. Lewin, E.M. Pearce, K. Levon, A. Mey-Marom, M. Zammarano, C.A. Wilkie, B.N. Jang, Nanocomposites at elevated temperatures: migration and structural changes, Polym. Adv. Technol. 17 (2006) 226-234;

(b) M. Lewin, Reflections on migration of clay and structural changes in nanocomposites, Polym. Adv. Technol. 17 (2006) 758-763;

(c) Y. Tang, M. Lewin, New aspects of migration and flame retardancy in polymer nanocomposites, Polym. Degrad. Stab. 93 (2008) 1986-1995;

(d) A. Fina, F. Cuttica, G. Camino, Ignition of polypropylene/montmorillonite nanocomposites, Polym. Degrad. Stab. 97 (2012) 2619-2626.

[10] M. Zammarano, J.W. Gilman, M. Nyden, E.M. Pearce, M. Lewin, The role of oxidation in the migration mechanism of layered silicate in poly(propylene) nanocomposites, Macromol. Rapid. Comm. 27 (2006) 693-696.

[11] (a) J.V. Gilman, Flammability and thermal stability studies of polymer layeredsilicate (clay)/nanocomposites, Appl. Clay Sci. 15 (1999) 31-49;

(b) M. Zanetti, T. Kashiwagi, L. Falqui, G. Camino, Cone calorimeter combustion and gasification studies of polymer layered silicate nanocomposites, Chem. Mater. 14 (2002) 881-887;

(c) B. Schartel, A. Weiß, H. Sturm, M. Kleemeier, A. Hartwig, C. Vogt, Layered silicate epoxy nanocomposites: formation of the inorganic-carbonaceous fire protection layer, Polym. Adv. Technol. 22 (2011) 1581-1592;

(d) B. Schartel, A. Weiß, SEM/EDX: advanced investigation of structured fire residues and residue formation, Polym. Test. 31 (2012) 606-619.

[12] F. Bellucci, G. Camino, A. Frache, A. Sarra, Catalytic charring evolatilization competition in organoclay nanocomposites, Polym. Degrad. Stab. 92 (2007) $425-436$.
[13] (a) M.G. Li, Y.Z. Wan, Z.F. Gao, G.Y. Xiong, X.M. Wang, C.B. Wan, H.L. Luo, Preparation and properties of polyamide 6 thermal conductive composites reinforced with fibers, Mater. Des. 51 (2013) 257-261;

(b) G. Wróbel, S. Pawlak, G. Muzia, Thermal diffusivity measurements of selected fiber reinforced polymer composites using heat pulse method, Arch. Mater. Sci. Eng. 48 (2011) 25-32.

[14] (a) G. Kalácska, R. Keresztes, L. Földi, S.Z. Klébert, Z. Károly, L. Zsidai, Thermal conductivity of plasma modified polyethylene terephthalate and polyamide- 6 layers, Express Polym. Lett. 10 (2016) 373-380;

(b) S.M. Ha, O.H. Kwon, Y.G. Oh, Y.S. Kim, S.G. Lee, J.C. Won, K.S. Cho, B.G. Kim, Y. Youngjae, Thermally conductive polyamide $6 /$ carbon filler composites based on a hybrid filler system, Sci. Technol. Adv. Mater. 16 (2015) 065001;

(c) S.T. Zhou, L. Yu, X. Song, J. Chang, H.W. Zou, M. Liang, Preparation of highly thermally conducting polyamide 6/graphite composites via low-temperature in situ expansion, J. Appl. Polym. Sci. 131 (2014) 39596.

[15] (a) S. Vyazovkin, C.A. Wight, Model-free and model-setting approaches to kinetic analysis of isothermal and nonisothermal data, Thermochim. Acta 340 (1999) 53-68;

(b) L. Dai, L.Y. Wang, T.Q. Yuan, J. He, Study on thermal degradation kinetics of cellulose -graft-poly(L-lacticacid) by thermogravimetric analysis, Polym. Degrad. Stab. 99 (2014) 233-239;

(c) B. Wu, Y.Z. Wang, X.L. Wang, Kinetics of thermal oxidative degradation of phosphorus-containing fame retardant copolyesters, Polym. Degrad. Stab. 76 (2002) 401-409.

[16] (a) J.D. Cooney, M. Day, D.M. Wiles, Kinetic and thermogravimetric analysis of the thermal oxidative degradation of flame-retardant polyesters, J. Appl. Polym. Sci. 29 (1984) 911-923;

(b) X.L. Chen, Y. Jie, Z. Luo, S.C. Hu, Z.W. Zhou, S.Y. Guo, Kinetics of thermooxidative degradation of zinc borate/microcapsulated red phosphorus with magnesium hydroxide in flame retarded polypropylene composites, J. Polym. Res. 16 (2009) 745-753.

[17] (a) W. Xie, Z. Gao, W.-P. Pan, D. Hunter, A. Singh, R. Vaia, Thermal degradation chemistry of alkyl quaternary ammonium montmorillonite, Chem. Mater. 13 (2001) 2979-2990;

(b) O.P. Heloise, A. Frache, E. Boccaleri, L. Marchese, G. Camino, Heat induced structure modifications in polymer-layered silicate nanocomposites, Macromol. Mater. Eng. 289 (2004) 783-786.

[18] (a) M. Zanetti, G. Camino, R. Mulhaupt, Combustion behaviour of EVA/fluorohectorite nanocomposites, Polym. Degrad. Stab. 74 (2001) 413-417. 